\title{
Actuarial cost and fiscal impact of expanding the Jordan Civil Insurance Programme for health coverage to vulnerable citizens
}

Yara Halasa-Rappel,, Taisser Fardous, ${ }^{2}$ Manal Jrasat, ${ }^{2}$ Ihab Al-Halaseh, ${ }^{3}$ Muien Abu-Shaer, ${ }^{4}$ Rami Hijazeen ${ }^{5}$ and Donald S. Shepard ${ }^{1}$

${ }^{1}$ The Heller School for Social Policy and Management, Brandeis University, Waltham, Massachusetts, United States of America. ${ }^{2}$ Health Economics Directorate, Ministry of Health, Amman, Jordan. ${ }^{3}$ Halaseh Auditor, Amman, Jordan. ${ }^{4}$ High Health Council, Ministry of Health, Amman, Jordan. ${ }^{5}$ NICEF Jordan Country Office, Amman, Jordan (Correspondence to: Yara Halasa-Rappel: yara@brandeis.edu; yarahalasa@yahoo.com).

\begin{abstract}
Background: Achieving universal health coverage is a strategic goal for the Government of Jordan. Estimating the cost of expanding health coverage to vulnerable Jordanians under the Civil Insurance Programme (CIP) is an important step towards achieving this goal.
\end{abstract}

Aims: This study aimed to estimate the cost and fiscal impact of expanding health insurance coverage to vulnerable Jordanians.

Methods: We identified and quantified vulnerable Jordanians and estimated their utilization and cost of health services provided at Ministry of Health facilities using allocation and macrocosting approaches. We calculated the annual actuarial cost per person and the fiscal impact of the expansion.

Results: It was estimated that $4.9 \%$ of Jordanians were vulnerable. On average, a vulnerable Jordanian used 1.25 ambulatory visits and 0.027 admissions fewer annually than a person insured by CIP. The annual cost (US\$ 79 million) and fiscal impact (US\$ 73 million) of expanding coverage to vulnerable Jordanians were due to more ambulatory services (20\%) and hospitalizations (80\%).

Conclusion: A combination of additional resources and improvement in system efficiencies may fund this expansion. Keywords: Universal health coverage; vulnerable population; actuarial cost; financial impact; macro-costing; hospital admissions; ambulatory visits; Jordan

Citation: Halasa-Rappel Y; Fardous T; Jrasat M; Al-Halaseh I; Abu-Shaer M; Hijazeen R; et al. The actuarial cost and fiscal impact of expanding the Jordan civil insurance programme for health coverage to vulnerable citizens. East Mediterr Health J. 2020;26(2):206-211. https://doi. org/10.26719/2020.26.2.206

Received: 27/11/17; accepted: 11/07/18

Copyright @ C World Health Organization (WHO) 2020. Open Access. Some rights reserved. This work is available under the CC BY-NC-SA 3.0 IGO license (https://creativecommons.org/licenses/by-nc-sa/3.o/igo).

\section{Introduction}

Ensuring access to quality, safe, effective and affordable essential healthcare services is a strategic goal for the Government of Jordan $(1,2)$, and providing health coverage to vulnerable Jordanians is a critical step to achieving universal health coverage (3). Jordan's policies build on evidence from the international literature around the benefits of universal health coverage, particularly for low-income people (4). A recent model projected 97 million lives could be saved during 2016-2030 across 67 lowand middle-income countries from achieving universal health coverage and related policies (5).

In $2015,63.4 \%$ of Jordanians had some kind of formal health insurance, $31.9 \%$ were uninsured, and $4.7 \%$ were uninsured but protected through a royal decree (6). The public sector covers $52.1 \%$ of Jordanians, which comprises the Civil Insurance Programme (CIP) (26.4\% of Jordanians), Royal Medical Services (24.1\%), and university hospitals (1.6\%). The private sector covers $7.9 \%$ of the population. The United Nations Relief and Works Agency (UNRWA) covers the primary healthcare costs of $1.6 \%$ of the population, while other agencies, such as professional unions, cover $1.6 \%$, and those covered from outside Jordan comprise $0.3 \%(1)$.
Lack of formal health insurance coverage does not mean that those not formally insured are completely without financial protection. All residents can benefit from the subsided healthcare services provided at the Ministry of Health ( $\mathrm{MoH})$ facilities (1). Children enrolled at public schools receive healthcare through the school health programme, and most Jordanians who lack formal insurance coverage or means to pay for healthcare may receive medical assistance through the Royal Court and other agencies.

The CIP is a semiautonomous fund managed by the $\mathrm{MoH}$ and provides health coverage for $41.7 \%$ of Jordanians with formal health insurance. The CIP covers all government officials and their dependents for care at $\mathrm{MoH}$ facilities and other public and private facilities, based on a grading system structured according to the government officials' level and years of service (7). In recent years, the Government of Jordan took bold steps toward expanding health coverage. All children under 6 years of age, persons aged $\geq 70$ years, and citizens residing in the least fortunate and remote areas were exempt from user fees for health services provided at $\mathrm{MoH}$ facilities (6).

The CIP issues an insurance card to citizens classified as low income by the Ministry of Social Development; 
those eligible for safety net benefits; families whose head of household has $\geq 75 \%$ disability; families in which 1 member is an organ donor; and blood donors. Optional paid membership in the CIP is available for all citizens who wish to be enrolled and are not already covered, including pregnant women and those aged $\geq 65$ years. The premium progressively increases with age (1). Despite these measures, vulnerable Jordanians may face limitations in accessing care, particularly for specialized services. This article should help Jordan, and other countries in the region, to estimate the cost of expanding their health insurance programmes to cover vulnerable populations.

The objective of this study was to estimate the cost and fiscal impact of expanding health insurance coverage to vulnerable Jordanians to assist the Government of Jordan in moving toward universal health coverage. Specifically, we estimated the annual actuarial cost of covering a vulnerable Jordanian through the CIP and the fiscal impact on the Government of Jordan of expanding coverage to this vulnerable population in 2016. For the purpose of this study, vulnerable Jordanians were defined as individuals in households with US\$ 1438 or less annual overall expenditure per household member, and lack health protection. This segment of the population is at high risk of falling below the poverty line, and possibly crossing in and out of poverty intermittently (8).

\section{Methods}

\section{Study design}

We derived the person-level cost of expanding health coverage for 2016 by multiplying utilization data obtained from the Jordan Healthcare Utilization and Expenditure Survey 2010 (9) times the unit costs of the corresponding healthcare services. We derived unit costs from the Jordanian National Health Accounts 2009-2016 (10-15), $\mathrm{MoH}$ statistics (16-22), 3 Delphi panels of $\mathrm{MoH}$ experts from the 12 governorates in Jordan, and CIP expenditure. We then estimated the actuarial cost of expanding health coverage to uninsured Jordanians and the fiscal impact of expanding health coverage to vulnerable Jordanians.

\section{Annual utilization rate}

We used the Jordan Healthcare Utilization and Expenditure Survey 2010 (9) to estimate the number of annual per capita ambulatory visits at $\mathrm{MoH}$ facilities and at other healthcare providers facilities, and the annual per capita admission rates at $\mathrm{MoH}$ hospitals and at hospitals run by other providers for Jordanians with CIP coverage and those with no insurance coverage. To estimate the expected increase in demand from an expansion of health insurance, we assumed, as justified below, that uninsured vulnerable Jordanians would have a similar healthcare utilization pattern to those covered under the CIP. The difference between utilization rates of those with CIP coverage and uninsured Jordanians was the expected increase in per capita ambulatory visits and hospital admissions for uninsured Jordanians if they were offered the CIP expansion coverage.

\section{Cost of services}

To estimate the person-level cost to the Government of Jordan, which funds both the MoH and CIP, we estimated the cost of an ambulatory service (health centre, outpatient visit, or emergency room visit) and a hospital admission sought at $\mathrm{MoH}$ facilities or other providers contracted by the CIP. Based on expert opinion from the first Delphi panel, we used the expenditure allocation approach to estimate the cost of providing healthcare services at $\mathrm{MoH}$ facilities after allocating central management and training costs to $\mathrm{MoH}$ centres and hospitals. A report by Shepard et al. (2017) provides more details (7). We included all expenditure incurred at $\mathrm{MoH}$ facilities regardless of the source of finance (11-15).

To estimate the average unit costs of services provided at $\mathrm{MoH}$ hospitals, we used the macro costing approach with relative values from the international literature to derive the cost per inpatient bed day and cost per outpatient visit $(10,23,24)$, as described previously (7). This approach helped us pool the cost among populations regardless of their health status. We used the $\mathrm{MoH}$ annual statistical reports to obtain the $\mathrm{MoH}$ hospitals' statistics for 2009-2015 (16-22).

For care provided at health centres, we excluded expenditure on public health activities (e.g., environmental health and health promotion activities) based on the second Delphi panel's estimates. We converted vaccination services provided during the national vaccination campaigns into equivalent health centre visits using an adjustment factor obtained from the third Delphi panel (one vaccination service equals 0.205 curative visits). We then calculated the cost of a curative visit to a $\mathrm{MoH}$ health centre by dividing the total annual cost by the number of visits.

We used a weighted average to estimate the cost of any ambulatory service provided at the $\mathrm{MoH}$ facilities (both health centres and outpatients clinics at $\mathrm{MOH}$ hospitals). We adjusted the unit costs to 2016 Jordanian dinars (JD) from the original years using gross domestic product per capita, averaged the resulting 7 years' values as our best estimate of unit costs, and then converted the cost to 2016 US dollars (1 JD = US\$1.41) (25).

To estimate the CIP expenditure for services provided outside $\mathrm{MoH}$ facilities, we obtained the annual CIP expenditure on primary and secondary care received outside $\mathrm{MoH}$ facilities using the National Health Accounts data and derived the cost per enrolee by dividing these aggregate costs by the number of CIP enrolees by setting (i.e., primary care or hospital) (11-15).

\section{Annual actuarial cost per person}

The Government of Jordan subsidizes $\mathrm{MoH}$ services to all residents. We collected and analysed patient charges from $\mathrm{Al}$-Bashier Hospital, one of the major $\mathrm{MoH}$ hospitals, which showed that, for an outpatient visit, the Government of Jordan covers $97 \%$ and $73 \%$ of direct medical costs of outpatient services provided to individuals with CIP insurance and uninsured Jordanians, respectively. 
For an admission at this MoH hospital, the Government of Jordan covers $100 \%$ and $64 \%$ of services provided to individuals with CIP insurance and uninsured Jordanians, respectively (16-22). These allocations were similar to estimates from the second Delphi panel of $\mathrm{MoH}$ officials.

We defined the actuarial cost as the cost that an insurer would incur in covering the economic cost of expected healthcare utilization. We estimated this actuarial cost per person for a Jordanian covered under the CIP programme and for an uninsured Jordanian by multiplying the products of the unit cost of each type of service (ambulatory visits and admissions) by its utilization rate. We then estimated the differences in the actuarial cost between CIP enrolees and uninsured Jordanians. This difference was the additional cost per person to the Government of Jordan associated with expanding the CIP to cover uninsured vulnerable Jordanians, adjusting for the current level of Government subsidies for healthcare services offered at $\mathrm{MoH}$ facilities.

\section{Fiscal impact to the Government of Jordan}

The fiscal impact is the net cost to the Government of Jordan after adjusting for costs already being incurred by the $\mathrm{MoH}$ for the current use of $\mathrm{MoH}$ services by uninsured Jordanians and changes in CIP revenue collected at $\mathrm{MoH}$ facilities. We estimated the aggregate fiscal impact under the proposed CIP expansion as the individual fiscal impact multiplied by the size of the population to be covered.

\section{Sensitivity analysis}

We used probabilistic sensitivity analysis to address the uncertainties in our cost estimates. We used the normal distribution to estimate the cost of providing healthcare services at $\mathrm{MoH}$ facilities, and CIP expenditures per CIP beneficiary for healthcare services provided outside $\mathrm{MoH}$ facilities. The mean and standard deviation (SD) of this distribution were calculated from the average unit costs of an ambulatory visit, admission, and CIP expenditure for care provided outside $\mathrm{MoH}$ facilities in 20092017. For each sensitivity analysis, we performed 1000 Monte Carlo simulations with independent drawing for each parameter. We calculated 95\% confidence intervals (CIs) of overall costs of ambulatory visits, admissions, and CIP expenditures for care provided outside $\mathrm{MoH}$ facilities based on the Monte Carlo simulations. The 95\% CIs of components separated between those covered by the CIP and uninsured were based on the SDs in the Jordan Healthcare Utilization and Expenditure Survey 2010 (9). We considered the variation in utilization for overall costs as negligible because of the large sample size (59 ooo individuals) in the survey (9).

\section{Results}

The annual per capita utilization rates [mean (SD)] for a CIP beneficiary were 4.44 (13.51) for ambulatory visits, of which, 1.46 (4.11) occurred at $\mathrm{MoH}$ facilities, and 0.084 (2.984) admissions, of which, 0.049 (0.606) occurred at $\mathrm{MoH}$ hospitals and 0.035 (0.408) outside $\mathrm{MoH}$ hospitals.
The annual per capita utilization rates for an uninsured Jordanian were 3.17 (12.56) for ambulatory visits, of which, 0.44 (2.36) occurred at $\mathrm{MoH}$ facilities, and 0.045 (1.394) admissions, of which, 0.049 (0.606) occurred at MoH hospitals. On average, CIP beneficiaries used 1.02 (4.74) more ambulatory visits and had 0.027 (0.664) more hospital admissions at $\mathrm{MoH}$ facilities per person per year compared to uninsured Jordanians. They also had 0.25 (17.66) more annual ambulatory visits and 0.012 (0.493) more admissions to other health providers compared to the uninsured Jordanians (9). While these SDs are several times the corresponding means, the standard errors of the means for the groups and differences between them are small due to the number of individuals (59 000) in the underlying survey.

The average unit cost of a visit at $\mathrm{MoH}$ health centre and $\mathrm{MoH}$ hospital ambulatory visit (outpatient and emergency) was US\$ 11.61 (3.85) and US\$ 55.49 (5.22), respectively. The weighted average of an ambulatory visit at $\mathrm{MoH}$ facilities (hospitals and health centres) was US\$23.12 (4.21). The average cost of an admission at $\mathrm{MoH}$ facilities was US\$ 541.02 (52.44). CIP expenditure per CIP beneficiary for services provided outside $\mathrm{MoH}$ facilities was US\$ 5.67 (1.05) for ambulatory care and US\$ 166.07 (34.31) for admissions.

The total annual actuarial cost per CIP enrolee was US\$240.80 (95\% CI) (US\$ 163.11-304.86). This cost included the entire cost of inputs for producing health services at $\mathrm{MoH}$ facilities and acquiring services from other healthcare providers. The actuarial cost to the CIP to provide coverage to an uninsured Jordanian was US\$ 43.50 (US\$ 29.67-47.26) for services provided at $\mathrm{MoH}$ facilities and US\$171.74 (US\$103.32-243.03) for services provided by other providers. The additional actuarial cost per uninsured Jordanian was US\$ 215.22 (US\$ 143.67283.20) (Table 1).

Revenue from services provided at $\mathrm{MoH}$ facilities varied by insurance status. The annual per capita outof-pocket payment by an uninsured Jordanian for an ambulatory visit was US\$ 11.33 (US\$ 10.17-12.49) compared to US\$2.92 (US\$1.53-4.31) for those covered by the CIP. The annual per capita out-of-pocket payment by uninsured Jordanians for admissions at $\mathrm{MoH}$ hospitals was US\$ 9.04 (US\$ 7.75-10.33] compared to US\$ 1.57 (US\$ 1.16-1.98) for those covered by the CIP.

Expansion of health coverage to uninsured Jordanians would reduce CIP revenues by US\$ 8.41 (US\$ 6.60-10.22) per person to be covered from ambulatory services and US\$ 7.47 (US\$ 6.12-8.82) from inpatient revenue, with an overall revenue loss of US\$ 15.88 (US\$ 12.72-19.04) per person to be covered.

We derived the fiscal impact by combining the expected loss in revenue per person to the CIP with the actuarial cost. The overall cost to the Government of Jordan or fiscal impact was US\$223.20 (US\$ 159.55299.08) per person to be covered (Figure 1). The aggregate cost for 326082 vulnerable Jordanians would be US\$ 73 million (US\$ 52-98 million). This cost could be broken down by settings as $20 \%$ due to ambulatory services 
Table 1 Current cost paid by Government of Jordan for Jordanians with CIP coverage and uninsured Jordanians, and estimated additional cost if uninsured Jordanians were offered coverage through CIP

\begin{tabular}{lcccccccccc} 
Benefit & \multicolumn{3}{c}{ CIP enrolees } & \multicolumn{3}{c}{ Uninsured } & \multicolumn{4}{c}{ Differences } \\
setting & Ambulatory & Admissions & Both & Ambulatory & Admissions & Both & Ambulatory & Admissions & Both \\
\hline MoH facilities & 42.05 & 27.02 & 69.06 & 13.23 & 12.34 & 25.58 & 28.82 & 14.68 & 43.50 \\
Outside $\mathrm{MoH}$ & 5.67 & 166.07 & 171.74 & 0.00 & 0.00 & 0.00 & 5.67 & 166.07 & 171.74 \\
\hline Total & $\mathbf{4 7 . 7 1}$ & $\mathbf{1 9 3 . 0 9}$ & $\mathbf{2 4 0 . 8 0}$ & $\mathbf{1 3 . 2 3}$ & $\mathbf{1 2 . 3 4}$ & $\mathbf{2 5 . 5 8}$ & $\mathbf{3 4 . 4 9}$ & $\mathbf{1 8 0 . 7 3}$ & $\mathbf{2 1 5 . 2 2}$ \\
\hline
\end{tabular}

Results are per person in 2016 in US\$. CIP = Civil Insurance Programme; $\mathrm{MoH}=$ Ministry of Health.

and $80 \%$ to inpatient services, and by origin to $94 \%$ due to actuarial cost of additional services and $6 \%$ loss of revenue to the CIP.

\section{Discussion}

We found that expanding the CIP to uninsured vulnerable Jordanians would cost US\$ 241 per person per year or US\$ 79 million per year under a scheme similar to that offered to government officials. Our results suggest that the Government of Jordan could expand coverage to vulnerable Jordanians under the CIP with an annual additional cost of US\$223.20 per person. The aggregate cost and aggregate additional cost would be US\$ 79 million and US\$ 73 million, respectively. This expansion would be affordable and represent only $3.5 \%$ of public sector health expenditure in Jordan (15), and would reduce the percentage of Jordanians who lack health coverage from $32 \%$ to $27 \%$ (6). By providing coverage for 1 in 6 uninsured Jordanians - likely the neediest - this policy would be a positive step towards universal coverage.

While expanding coverage might require additional resources for the $\mathrm{MoH}$ facilities to maintain and improve service capacity and quality, the expansion may also improve efficiency of the health system and even reduce overall health expenditure at the national level, if planned and implemented appropriately. Currently, all Jordanian

Figure 1 Cost of providing insurance to vulnerable Jordanians, combining the net costs of services plus loss of current revenues, per person in 2016 (US\$)

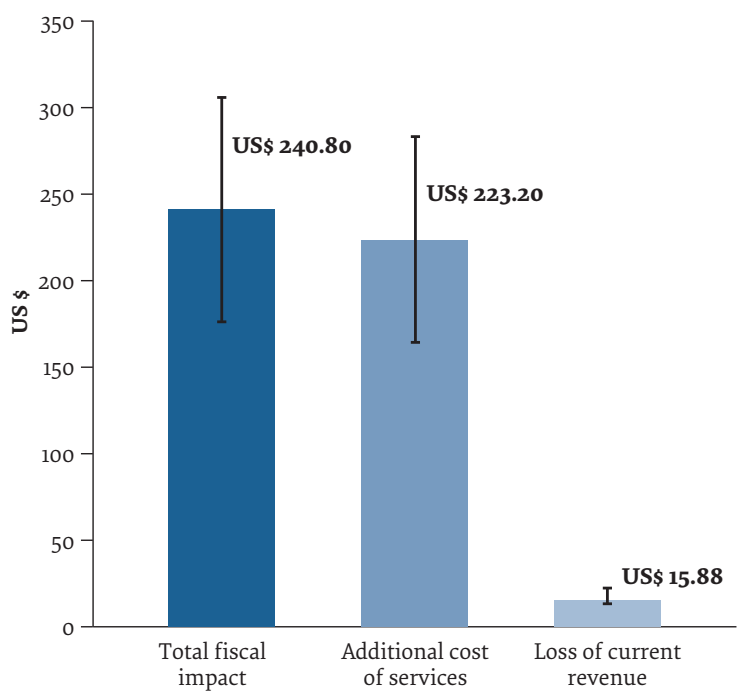

citizens can benefit from the highly subsided services provided at $\mathrm{MoH}$ facilities (1), and most Jordanians who lack formal insurance coverage or means to pay for health care can receive medical assistance through the Royal Court and other agencies. In 2013, the Royal Court paid US\$254 million to treat 110000 cases, mostly outside the $\mathrm{MoH}$ facilities (average of US\$2307 per case). While this system helps avert catastrophic expenditure, its absence of active management, lack of review of the care plan or its cost, and the perverse incentive of covering only uninsured Jordanians undermine efforts to expand health coverage in a systematic way.

Moving forward, the Government of Jordan and $\mathrm{MoH}$ should consider several options to fund this expansion of CIP coverage. Rechannelling funds from the Royal Court to the CIP should be considered to cover vulnerable Jordanians and establish contract mechanisms with other health providers for services provided outside the $\mathrm{MoH}$ to uninsured Jordanians. Funding CIP expansion to vulnerable Jordanians would amount to $29 \%$ of the Royal Court expenditure in 2013. Another funding source might be the international community. Jordan has been covering the health care of Syrian refugees in Jordan for $>5$ years, and the international community should consider assisting the Government of Jordan in its quest to achieve universal health coverage, to mitigate any potential tension between citizens and refugees due to shrinking resources. Additionally, the Government of Jordan might consider earmarking some of the sin taxes on tobacco and sweetened drinks to the $\mathrm{MoH}$. Moreover, improving $\mathrm{MoH}$ system efficiency might generate some savings that could be used to cover this vulnerable population (26). These efficiencies might include developing and implementing guidelines to deal with chronic diseases and cancer, and utilizing the midlevel workforce to conduct outreach activities and patient follow-up.

This study had several limitations. First, our estimate was based on a comparison between Jordanians insured under the CIP and uninsured Jordanians. We assumed these two groups had similar needs. Two offsetting factors might support this assumption: it is possible that the uninsured population is in poorer health and, if insured, would use more services, incurring higher costs than those estimated here. However, vulnerable Jordanians might have more challenges in accessing services, which would lead to lower utilization. We examined the 
enrolment of those with low incomes under the CIP and their utilization of $\mathrm{MoH}$ services in 2011-2015. We found that only $11 \%$ of those on low incomes were covered by the CIP and their utilization rate was high, an annual 7 visits per low-income person enrolled, suggesting that those who need care applied and obtained coverage. Second, our utilization data were from 2010. While major changes at the health-system level did occur due to the subsequent influx of Syrian refugees, it is unlikely that individual health-seeking behaviour changed for the Jordanian population. We analysed the utilization rate at $\mathrm{MoH}$ centres for those with CIP coverage and those categorized as having low incomes in 2009-2014 and found a consistent rate of utilization. Finally, the current analysis was based on the current level of Government subsidies and donor support for healthcare services offered at $\mathrm{MoH}$ facilities. Future policy changes that increase out-ofpocket costs could lower utilization, while improved quality of care could result in higher utilization.

\section{Conclusion}

We estimated the cost of expanding healthcare coverage to vulnerable Jordanians to assist the Government of Jordan in achieving its goal of universal health coverage. The cost of expanding healthcare coverage for vulnerable Jordanians was US\$223.20 per person newly covered per year. A combination of additional resources and improvement in system efficiencies could fund this expansion.

Funding: UNICEF, Jordan Office.

Competing interests: None declared.

\section{Coût actuariel et impact fiscal de l'élargissement du Programme jordanien d'assurance civile à la couverture sanitaire des citoyens vulnérables}

\section{Résumé}

Contexte : La mise en place d'une couverture sanitaire universelle est un objectif stratégique pour le Gouvernement jordanien. L'estimation du coût de l'élargissement de la couverture sanitaire aux Jordaniens vulnérables dans le cadre du Programme d'assurance civile (CIP) est une étape importante dans la réalisation de cet objectif.

Objectifs : La présente étude visait à estimer le coût et l'impact fiscal de l'élargissement de la couverture d'assurance maladie aux Jordaniens vulnérables.

Méthodes : Nous avons identifié et quantifié les Jordaniens vulnérables, puis estimé leurs utilisations et le coût des services de santé fournis dans les établissements du ministère de la Santé au moyen d'approches basées sur l'allocation de crédit et l'estimation du coût par macro-éléments. Nous avons calculé le coût actuariel annuel par personne et l'impact fiscal de l'élargissement du programme.

Résultats : Selon les estimations, 4,9 \% des Jordaniens étaient vulnérables. En moyenne, un Jordanien vulnérable effectuait 1,25 visite ambulatoire et avait 0,027 hospitalisation de moins par an qu'une personne couverte par le CIP. Le coût annuel (USD 79 millions) et l'impact fiscal (USD 73 millions) de l'élargissement de la couverture aux Jordaniens vulnérables étaient dus à l'augmentation des services ambulatoires (20\%) et des hospitalisations (80\%).

Conclusion : L'association de ressources supplémentaires et d'une amélioration de l'efficacité du système pourrait permettre de financer cet élargissement du programme.

$$
\begin{aligned}
& \text { التكلفة الأكتوارية و الأثر المالي للتوسع في برنامج التأمين الصحي المدني الأردني لتحقيق التغطية الصحية للفئات } \\
& \text { المستضعفة من المو اطنين. } \\
& \text { يارا هلسة رابيل، تيسير فردوس، منال جريسات، إيهاب الهلسة، معين أبو الشعر، رامي حجازين، دونالد شيبرد }
\end{aligned}
$$

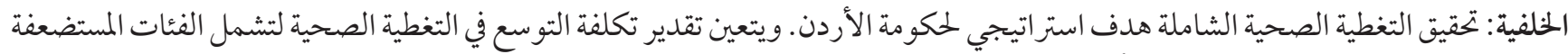

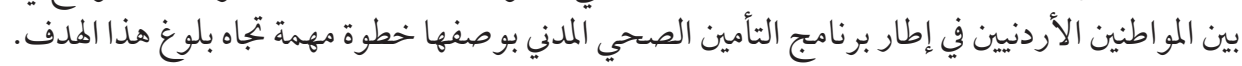

$$
\begin{aligned}
& \text { الأهداف: الهدف من هذه الدراسة هو تقدير تكلفة الأثر المالي لتوسيع تغطية التأمين الصحي ليشمل الفئات المستضعفة من المو اطنين الأردنين. }
\end{aligned}
$$

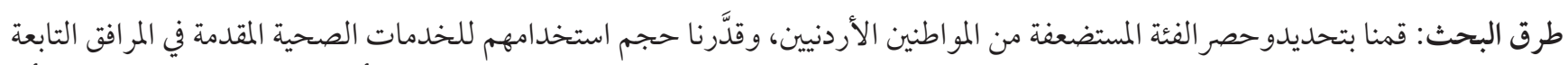

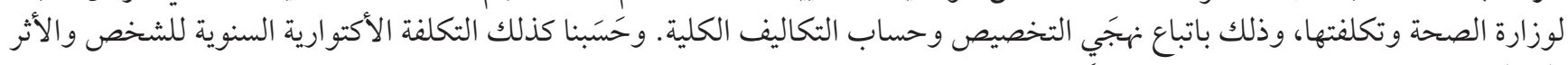

$$
\begin{aligned}
& \text { المالي للتوسع. }
\end{aligned}
$$

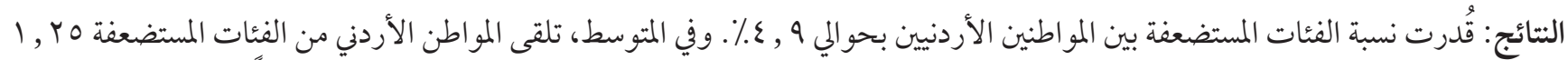

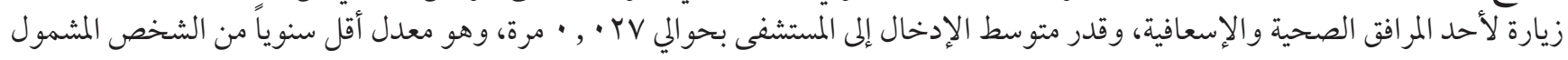




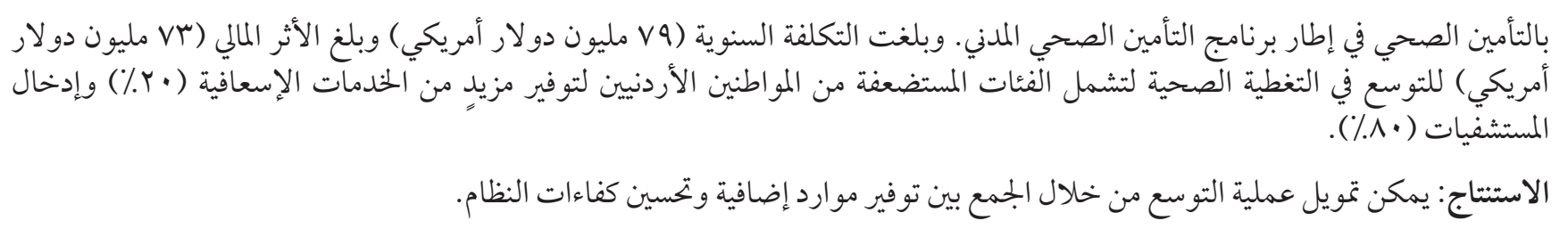

\section{References}

1. The national strategy for health sector in Jordan 2016-2020. Amman: High Health Council; 2016 (http://www.nationalplanningcycles.org/sites/default/files/planning_cycle_repository/jordan/national_strategy_for_health_sector_2016-2020_jordan.pdf, accessed 10 August 2019).

2. Jordan 2025: a national vision and strategy. Amman: Ministry of Planning and International Cooperation; 2015 (http://inform. gov.jo/Portals/o/Report\%20PDFs/0.\%20General/j02025part1.pdf, accessed 10 August 2019).

3. Transforming our world: the 2030 Agenda for Sustainable Development. Geneva: United Nations; 2015 (https://sustainabledevelopment.un.org/post2015/transformingourworld, accessed 10 August 2019).

4. Moreno-Serra R, Smith PC. Does progress towards universal health coverage improve population health? Lancet. 2012 Sep 8;380(9845):917-23. http://dx.doi.org/10.1016/So140-6736(12)61039-3 PMID:22959388

5. Stenberg K, Hanssen O, Edejer TT, Bertram M, Brindley C, Meshreky A, et al. Financing transformative health systems towards achievement of the health Sustainable Development Goals: a model for projected resource needs in 67 low-income and middle-income countries. Lancet Glob Health. 2017 Sep 1;5(9):e875-87. http://dx.doi.org/10.1016/S2214-109X(17)30263-2 PMID:28728918

6. General population and housing census 2015. Main results. Amman: Department of Statistics; 2016 (http://dosweb.dos.gov.jo/ wp-content/uploads/2017/08/Census2015_Eng.pdf, accessed 10 August 2019).

7. Shepard D, Halasa-Rappel Y, Al-Halaseh I, Fardous T, Jrasat M, Abu-Shaer M. Health care cost study at Ministry of Health and the cost and financial impact of expanding the Civil Insurance Program to vulnerable Jordanians and Syrian refugees. Amman: UNICEF Jordan Country Office, 2017.

8. Background document for the national poverty reduction strategy. Hashemite Kingdom of Jordan. The Earth Institute, Columbia University; 2012 (http://www.mop.gov.jo/EchoBusV3.o/SystemAssets/97742757-5f15-492a-8246-603doabee8b2.pdf, accessed 10 August 2019).

9. Department of Statistics, Jordanian Ministry of Health. Jordan healthcare utilization and expenditure survey 2010. Amman: Ministry of Health; 2010.

10. Adam T, Evans DB, Ying B, Murray CJ. Variability in costs across hospital wards. A study of Chinese hospitals. PLoS One. 2014 May 29;9(5):e97874. http://dx.doi.org/10.1371/journal.pone.0097874 PMID:24874566

11. Jordan national health accounts 2009. Technical report no. 3. Amman: High Health Council; 2012.

12. Jordan national health accounts 2010-2011. Technical report no. 4. Amman: High Health Council; 2013.

13. Jordan national health accounts 2012. Technical report no. 5. Amman: High Health Council; 2014.

14. Jordan national health accounts 2013. Technical report no. 6. Amman: High Health Council; 2016.

15. Jordan national health accounts 2014-2015. Unpublished.

16. Department of Statistics and Information. Annual statistical report. Amman: Ministry of Health; 2009.

17. Department of Statistics and Information. Annual statistical report. Amman: Ministry of Health; 2010.

18. Department of Statistics and Information. Annual statistical report. Amman: Ministry of Health; 2011.

19. Department of Statistics and Information. Annual statistical report. Amman: Ministry of Health; 2012.

20. Department of Statistics and Information. Annual statistical report. Amman: Ministry of Health; 2013.

21. Department of Statistics and Information. Annual statistical report. Amman: Ministry of Health; 2014.

22. Department of Statistics and Information. Annual statistical report. Amman: Ministry of Health; 2015.

23. Shepard DS, Hodgkin D, Anthony YE. Analysis of hospital costs: a manual for managers. Geneva: World Health Organization; 2000 (https://apps.who.int/iris/bitstream/handle/10665/42197/9241545283.pdf?sequence=1\&isAllowed=y, accessed 10 August 2010).

24. Adam T, Evans DB. Determinants of variation in the cost of inpatient stays versus outpatient visits in hospitals: a multi-country analysis. Soc Sci Med. 2006 Oct;63(7):1700-10. http://dx.doi.org/10.1016/j.socscimed.2006.04.023 PMID:16769168.

25. Department of Statistics. Jordan Gross National Product 1999 through 2016.

26. Towards universal health coverage: a comprehensive review of the health financing system in Jordan. Report no: ACS9635. Washington, DC: World Bank; 2014. 